\title{
Investigating the impact of GDP and distance variables in the gravity model using sign and rank tests
}

\author{
Berislav ŽMUK*, Hrvoje JOŠIĆ**
}

\begin{abstract}
The gravity model of trade has been a workhorse of international economics over the last fifty years. The main variables incorporated in the standard gravity model of trade are gross domestic product of trading countries and distance between them. The previous investigation has been limited only to an econometric estimation and evaluation of regression coefficients in the gravity model and their significance. However, until now there has been no research on investigating the impact of GDP and Distance variables in the gravity model by using sign and rank tests, which is the objective of this paper. This paper adds to the existing literature by employing non-parametric approach to estimating the impact of variables in the gravity model by using sign and rank tests in the case of World countries. The results of the analysis have shown that the GDP variable exhibits a higher distribution of positive signs achieved in the sign test and presents less average errors in the rank test in predicting bilateral trade imports with regards to the Distance variable. Furthermore, the GDP variable also has a relatively higher impact in the gravity model than the Distance variable.
\end{abstract}

Keywords: gravity model, World countries, sign and rank tests, RMSE, MAPE

\section{Introduction}

The gravity model has been firstly applied in the field of international trade in 1962 by Jan Tinbergen (Tinbergen, 1962) but the origins of the gravity model go back to 1687 and the formulation of law of universal gravity developed by Isaac Newton. The law of universal gravity states that the gravitational force between two bodies is proportional to their masses and inversely proportional to the square of distance between them. The gravity model in international economics puts this

\footnotetext{
*Berislav ŽMUK is Assistant Professor at the Faculty of Economics and Business in Zagreb, Zagreb, Croatia; e-mail: bzmuk@efzg.hr.

${ }^{* *}$ Hrvoje JOŠIĆ is Assistant Professor at the Faculty of Economics and Business in Zagreb, Zagreb, Croatia; e-mail: hjosic@efzg.hr.
} 
relation into an economic context (Starck, 2012). The variable which usually represents country's economic size in the empirical literature is the gross domestic product (GDP) while the distance between countries is most often approximated with the aerial distance between countries' capital cities. The gravity model is used to correctly approximate bilateral trade flows and has long been one of the most successful and stable empirical models in economics (Salvatici, 2013).

McCallum (1995) proved that national borders matter in the case of Canada's intra-province trade being 23 times more intense than the trade between Canada and the United States. Prior to the general acceptance of the gravity model, there have been several criticisms related to its not having or lacking a strong theoretical basis, Kareem and Kareem (2014). Nevertheless, the theoretical foundation of the gravity model can be found in the work of Anderson (1979), Bergstrand (1985), Eaton and Kortum (2002), Anderson and van Wincoop (2003), Helpman et al. (2008), etc.

The previous investigation of the gravity model has been limited only to econometric specifications and the evaluation of regression coefficients in the gravity model and its significance. However, until now there has been no research related to the investigation of the variables' impact in the gravity model, which is the aim of this paper. The impact of GDP and Distance variables in the gravity model will be evaluated by calculation and analysis of positive (correct) signs achieved in the sign test and average errors between expected and actual ranks in the rank test. Therefore, this paper adds to the existing economic literature in this field of research by employing non-parametric approach to the estimation of the impact of GDP and distance variables in the gravity model by employing the sign and rank tests. This is a new idea using an old concept; the sign and rank tests are well known instruments for testing the Heckscher-Ohlin theory (Ohlin, 1933) and the Heckscher-OhlinVanek theorem specifically (Vanek, 1968; Kohler, 1991).

The sign test displays the percentage of cases in which a certain variable has been correct in predicting bilateral trade flows, in this paper imports, as the percent of distribution of positive signs. The sign test for the GDP variable will be calculated by comparing the difference between the actual GDP value of the import trade partner country and the average GDP value (the arithmetic mean of values for all import trade partner countries) with the difference between the actual imports value and the average imports value. If, for example, the actual value of GDP of the import trade partner country is higher than the average value, than the actual import value should be higher than the average import value. In that case the positive sign will be achieved in the sign test. The percentage of correct signs achieved in the sign test should be higher than $50 \%$ in order in order for the results to make sense, otherwise it becomes arbitrary and random. There are no defined certain thresholds in economic theory for the sign test to be valid in verifying a hypothesis. However, a higher percentage achieved in the sign test should support the hypothesis of the paper. On the other hand, the rank test, using the root mean square error (RMSA) 
and the mean absolute percentage error (MAPE), displays average errors between expected and actual ranks.

Analysis will be conducted for all World countries for which data were available. After that, the subsamples of countries will be analysed (CEE and EU countries) as well as Croatia as an individual country from Central and Eastern Europe having membership in the EU. It is expected that GDP and Distance variables will be significant in the model, achieving a strong performance in the sign test by having a very high distribution of positive signs. According to the stated objective of the paper, the hypotheses are as follows:

H1: The GDP and Distance variables will display a high performance in predicting bilateral trade imports in the gravity model.

H2: The GDP variable will have higher impact on bilateral trade imports than the Distance variable.

It will be interesting to see which variable will have greater impact on bilateral trade imports, since both variables have been considered as being part of a standard gravity model. The research conducted in this paper can shed new light in explaining the role of GDP and distance variables in the gravity model. Parametric tests can show the variables' significance but cannot precisely measure the performance and impact of each variable in the gravity model. The authors are aware that the use of non-parametric tests such as the sign and rank test can be considered statistically weak but are trying to make a progress in this field of research and test this approach. The economic implications of the results can be relevant for different actors and scientific community in general. Therefore, it would be important to prove the research hypotheses in this paper.

This paper is structured in six chapters. After the introduction, in literature review theoretical and empirical research on the gravity model of international trade is displayed. Special attention was dedicated to the recent methodological advances and specifications of the gravity model. The data and methodology section is presented in chapter two while the results and discussion on investigating the impact and precision of GDP and distance variables in the gravity model are shown in chapter three. The final chapter sums up the main conclusions of the paper, limitations of the study and gives guidelines for further investigations.

\section{Literature review}

In this chapter the theoretical foundation of the gravity model, recent methodological advances and specifications of the gravity model will be presented and discussed. The gravity model and its equation can be derived from different trade frameworks or theories. Anderson (1979) made a theoretical explanation of the 
gravity model based on the demand functions with constant elasticity of substitution. Krugman (1980) and Bergstrand (1985) derived the essence of the gravity model from the monopolistic competition, Deardorff (1998) derived it from the HeckscherOhlin theory while Eaton and Kortum (2002) obtained the theoretical justification of the gravity model from the Ricardo's theory of comparative advantages. The gravity model has also been used to analyse the economic impact of trade, free trade agreements, foreign direct investments, migrations, etc. While its theoretical justification is no longer a concern, a proper empirical estimation raises more questions.

De Benedictis and Taglioni (2011) recognised the issues in the empirical gravity model linked to trade which deserved to be mentioned. Those are the zero trade problem or the problem of missing trade, the choice of the proper estimator, dynamics and interdependence in the gravity models. Trade datasets often contain zeroes with the number of zeroes increasing with the higher level of data disaggregation. In that case the log-log model could not be constructed since the log of zero is undefined. Common estimation techniques to deal with trade zeroes and logarithmic transformation are the models proposed by Tobin (1958), Heckman (1979) and Helpman et al. (2008).

Almog et al. (2019) introduced an Enhanced Gravity Model (EGM) of trade, which combined the gravity model with the network approach within a maximumentropy framework. It provided a new econometrical framework in which the trade probabilities and trade volumes can be separately controlled. The role of economic size and distance has been remarkably stable over time across different countries using various econometric methods (Chaney, 2014). Based on the sample of 1,467 estimates of the distance regression coefficient in the gravity model equations in 103 papers, Disdier and Head (2008) came to the conclusion that the distance coefficient has been stable, hovering around 1 over more than a century of data. The $90 \%$ of estimates have been in the range between 0.28 and 1.55 with a slight increase in the distance coefficient since 1950s. The gravity model has been used for assessing the trade policy implications, particularly analysing the effects of Free Trade Agreements (FTA) on trade (Konstantinos et al., 2010).

Kreinovich and Sriboonchitta (2017) provided a quantitative justification for the gravity model. The authors derived a correspondent function of GDPs and distance between two countries describing the natural properties of the function such as additivity, scale-invariance and monotonicity. In structural gravity models, multilateral resistance terms (MRT) are an important departure from the analogy of the gravity model. According to MRT, the more the country is hesitant to trade with another country it will trade more with other countries, (Poissonnier, 2016). Ommitting MRT from estimated models induces bias errors, so Baldwin and Taglioni (2007) named it the gold medal error. 


\section{Data and methodology}

In this section, the data sources and methodology of the paper will be presented and elaborated. In Equation 1, a standard equation for the gravity model is displayed:

$$
F_{i j}=\beta_{0} \frac{G D P_{i}^{\alpha} G D P_{j}^{\beta}}{D_{i j}^{\gamma}}
$$

$F_{i j}$ are the bilateral trade flows (representing imports, exports or total trade), $\beta_{0}$ is a gravity constant, $G D P_{i}$ and $G D P_{j}$ are the gross domestic products of trading countries $i$ and $j, D_{i j}$ is an aerial distance between two countries' capital cities while $\alpha, \beta$ and $\gamma$ are the regression coefficients. Equation 1 can be transformed into linear form by employing natural logarithmic transformation Equation 2:

$$
\ln F_{i j}=\ln \beta_{0}+\alpha \ln G D P_{i}+\beta \ln G D P_{j}+\gamma \ln D_{i j}+\delta \ln \gamma_{i j}+\varepsilon_{i j}
$$

In the regression, $\gamma_{i j}$ represents all other variables that determine bilateral trade flows such as adjacency, common language and colonial links, currency board, regional trade agreements, remoteness, etc. In the original Tinbergen model (Tinbergen, 1962) the size of trade flows between any pair of countries was determined by the amount of exports a country $i$ is able to supply to country $j, M_{i}$, depending on its economic size, the size of the importing market $M_{j}$, measured by its gross national product and $\emptyset_{i j}$, the geographical distance between the two countries with the model expressed in log-log form (De Benedictis and Taglioni, 2011).

In this paper, the emphasis will be placed on investigating the performance of the main variables in the standard gravity model; the economic size and distance, measured by the gross domestic product (GDP) of trading countries and aerial distance between theirs' capital cities. The dependent variable in the specifications will be bilateral trade imports. Other variables $\gamma_{i j}$ have not been included in the analysis because the goal of the paper was to analyze the impact of GDP and Distance variables in the gravity model using the sign and rank tests only. Also, the same procedure could not be applied to other dummy variables. It will be interesting to see which variable will be more precise in estimating the bilateral trade imports. Data on imports of all products from the World by country are obtained from the WITS homepage and expressed in thousands of US dollars ${ }^{1}$. Data on GDPs of trade partner countries are provided from the World Bank homepage and expressed in

\footnotetext{
${ }^{1}$ WITS (2019), Imports by country all products from World, in thousands of US\$ (from https://wits.worldbank.org/).
} 
current US dollars ${ }^{2}$. Data on bilateral distances between capital cities are provided from the CEEPI's GeoDist database and Mayer and Zignago (2006). There are 174 countries included in the analysis in the period from 2000 to 2018 . The analysis is made for each of countries' bilateral trade imports. There are 363,405 unique pieces of data in the analysis for all observed countries. In the paper, the results are shown for one individual country, Croatia, for the group of countries (CEE and EU countries) and separately for the whole world. The analysis could be furthermore aggregated according to income level, geographical location, etc.

In Equations 3 and 4, the sign tests are displayed for the GDP and Distance variables. The GDP and Distance variables are paired with the Imports variable in order to test the performance of each variable (GDP or Distance) independently in the gravity model. The idea for the implementation of the sign test, as mentioned in the introductory part of the paper, is "borrowed" from the testing of the HeckscherOhlin-Vanek theorem. In the analysis we wanted to check whether bilateral trade imports are related with the GDP and Distance variable:

$$
\operatorname{Sign}\left(G D P_{j}-\frac{\sum_{j=1}^{n} G D P_{j}}{n}\right)=\operatorname{Sign}\left(M_{j}-\frac{\sum_{j=1}^{n} M_{j}}{n}\right)
$$

According to the sign test for the GDP variable, the sign of the difference between the actual GDP value of a country $j$, which is an import trade partner of a country $i, G D P_{j}$, and average GDP value of all $n$ import trade partner countries, $\frac{\sum_{j=1}^{n} G D P_{j}}{n}$, should be matched with the sign of the difference between actual imports value, $M_{j}$, and average imports value, $\frac{\sum_{j=1}^{n} M_{j}}{n}$. That is, if the GDP of the trade partner country $j$ is higher than the average GDP value of trade partner countries, than the imports from that country should be higher than the average imports and vice versa. In that case, the positive value will be achieved in the sign test. Therefore, the mean value is the demarcation line between the actual value and the value predicted by the sign test. The use of mean value as a demarcation value has a foothold in the gravity model itself where increased value of imports is positively correlated with the GDP of trade partner country. The efficiency of the model could be potentially further improved by using the median or mode value instead of the mean value:

$$
\operatorname{Sign}\left(d_{i j}-\frac{\sum_{j=1}^{n} d_{i j}}{n}\right)=\operatorname{Sign}\left(M_{j}-\frac{\sum_{j=1}^{n} M_{j}}{n}\right)
$$

2 World Bank (2019), GDP current US\$ (retrieved from https://data.worldbank. org/indicator/NY.GDP.MKTP.CD). 
The same procedure can be applied for the Distance variable. However, in this case shorter bilateral distances should be associated with the larger quantity of imports and larger bilateral distances with the smaller quantity of imports.

After the sign testing, the rank test should also shed some light on the precision of the GDP and Distance variables in the gravity model. In the process of ranking, a trade partner country $j$ having the highest value of exports to a country $i$ (its imports) will get the rank one, the second country will get the rank two, and so on. The same approach will be then used for ranking import trade partner countries according to the GDP variable. However, for the variable Distance, the import trade partner country with the smallest distance from the capital city of a country $i$ will get rank one. The rank test for the GDP and Distance variables are presented in Equations 5 and 6 separately.

$$
\begin{gathered}
\operatorname{Rank}\left(G D P_{j}\right) \sim \operatorname{Rank}(M)_{j} \\
\operatorname{Rank}\left(\min \left(\text { Distance }_{i j}\right) \sim \operatorname{Rank}\left(\max (M)_{j}\right)\right.
\end{gathered}
$$

Differences between expected ranks according to the GDP and Distance variables and average ranks according to the Imports variable will be calculated separately and observed as errors but only two will be presented: the root mean square error (RMSE) and the mean absolute percentage error (MAPE). The root mean square error of ranks will be calculated using the following equation:

$$
R M S E_{i t}=\sqrt{\frac{\sum_{j=1}^{n}\left(\text { ImportRank }_{\mathrm{jit}}-\text { GDPRank }_{\mathrm{jit}}\right)^{2}}{n_{i t}}},
$$

where $R M S E_{i t}$ is the root mean square error related to the $i$-th import country in year $t$, ImportRank $k_{j i t}$ is the rank of $j$-th import trade partner country in the year $t$ according to the value of the Import variable, GDPRank $k_{j i t}$ is the rank of $j$-th import trade partner country in year $t$ according to the value of the GDP variable and $n_{i t}$ is the number of import trade partner countries in year $t$. The mean absolute percentage error is calculated as follows:

$$
M A P E_{i t}=\frac{\sum_{j=1}^{n}\left|\frac{\text { ImportRank }_{\mathrm{jit}}-\text { GDPRank }_{\mathrm{jit}} \mid}{\operatorname{ImportRank}_{\mathrm{jit}}}\right|}{n_{i t}} \cdot 100
$$


where $M A P E_{i t}$ is the mean absolute percentage error related to the $i$-th import country in year $t$, ImportRank $_{j i t}$ is the rank of $j$-th import trade partner country in the year $t$ according to the value of the Import variable, GDPRank $k_{j i t}$ is the rank of the $j$-th import trade partner country in the year $t$ according to the value of the GDP variable, $n_{i t}$ is the number of import trade partner countries in year $t$. The root mean square error is given in absolute measure units, here ranks, whereas the mean absolute percentage error is given in percentages. The root mean square error is used to compare the size of rank errors between country groups and years. On the other hand, the mean absolute percentage error is used to determine whether the difference between ranks or errors is large or not. The value of MAPE higher than 50 percent can be interpreted as an inaccurate forecasting. The value of MAPE in the range of 20-50 percent can be interpreted as reasonable forecasting while the value of MAPE in the range of 10-20 percent can be interpreted as good forecasting. Lastly, the value of MAPE lower than 10 percent can be interpreted as highly accurate forecasting, Lewis (1982).

In order to estimate which variable, GDP or Distance, has a higher impact on the change of the Imports variable, standardized multiple linear regression models were estimated. The standardized values of variables were calculated by using the following equations:

$$
\begin{gathered}
\hat{y}_{i t}^{*}=\frac{y_{i t}-\bar{y}_{t}}{\sigma_{y_{t}}}, i=1,2, \ldots, n \\
x_{i j t}^{*}=\frac{x_{i j t}-\bar{x}_{j t}}{\sigma_{x_{j t}}}, i=1,2, \ldots, n, \quad j=1,2
\end{gathered}
$$

where $\hat{y}_{i}^{*}$ is the standardized value of imports related to the $i$-th import country in year $t, y_{i t}$ is the value of imports to a country $i$ in year $t, \bar{y}_{t}$ is the average imports in the observed countries in year $t, \sigma_{y_{t}}$ is the standard deviation of imports values in the observed countries in year $t, x_{i j t}^{*}$ is the standardized value of GDP or Distance related to $i$-th import country in year t, $x_{i j t}$ is the value of GDP or Distance to a country $i$ in year $t, \bar{x}_{j t}$ is the average GDP or Distance in the observed countries in year $t$ and $\sigma_{x_{j t}}$ is the standard deviation of GDP or Distance values in the observed countries in year $t$. The resulting multiple linear regression model with standardized values in year $t$ can be written as:

$$
\hat{y}_{i t}^{*}=\hat{\beta}_{1 t}^{*} x_{1 i t}^{*}+\hat{\beta}_{2 t}^{*} x_{2 i t}^{*}, i=1,2, \ldots, n,
$$


In regression models the Imports variable will be the dependent variable whereas the GDP and Distance variables will be independent variables with all variables being standardized beforehand. After that, the regression models will be estimated and the absolute values of estimated coefficients of independent variables will be compared. Lastly, the conclusion will be reached about which independent variable has a higher relative impact on the change of the dependent variable.

\section{Results and discussion}

In this section, the most important results of the paper will be discussed and elaborated. Firstly, the descriptive statistics of variables referring to imported values, the number of import trade partner countries to Croatia, the average import value of an import trade partner country and the distribution of import trade partner countries to Croatia according to the distance between the capitals in the observed period will be presented. After that, the results of the sign and ranks tests will be shown. Lastly, the multiple linear regression models, using standardized variables, will show which variable, GDP or distance, has a relatively higher impact on the Imports variable.

\subsection{Descriptive statistics}

According to Table 1, the total value of imports in Croatia in 2001 was 8,963 million US dollars and it increased to 26,929 million US Dollar in 2018, which is an increase in total imports value of $200.45 \%$ in 2018 compared to 2001.

Table 1. Value of imports and the number of import trade partner countries of Croatia in the period from 2001 to 2018

\begin{tabular}{cccc}
\hline Year & $\begin{array}{c}\text { Imported value, in } \\
\text { millions of US } \\
\text { dollars }\end{array}$ & $\begin{array}{c}\text { Number of import } \\
\text { trade partner } \\
\text { countries of Croatia }\end{array}$ & $\begin{array}{c}\text { Average import value per } \\
\text { importing country, in millions } \\
\text { of US dollars }\end{array}$ \\
\hline 2001 & 8,963 & 157 & 57.1 \\
\hline 2002 & 10,536 & 159 & 66.3 \\
\hline 2003 & 13,877 & 166 & 83.6 \\
\hline 2004 & 16,143 & 173 & 93.3 \\
\hline 2005 & 17,993 & 167 & 107.7 \\
\hline 2006 & 20,961 & 173 & 121.2 \\
\hline 2007 & 25,148 & 170 & 147.9 \\
\hline 2008 & 29,956 & 180 & 166.4 \\
\hline 2009 & 20,598 & 174 & 118.4 \\
\hline 2010 & 19,440 & 173 & 112.4 \\
\hline 2011 & 22,000 & 171 & 128.7 \\
\hline 2012 & 20,127 & 168 & 119.8 \\
\hline 2013 & 21,176 & 144 & 147.1 \\
\hline
\end{tabular}




\begin{tabular}{llll}
\hline 2014 & 21,886 & 140 & 156.3 \\
\hline 2015 & 19,619 & 136 & 144.3 \\
\hline 2016 & 20,868 & 139 & 150.1 \\
\hline 2017 & 23,356 & 127 & 183.9 \\
\hline 2018 & 26,929 & 137 & 196.6 \\
\hline
\end{tabular}

Source: Authors' calculations

On the other hand, the number of countries from which Croatia imported goods and services was lower in 2018 than in 2001. The number of importing countries was the highest in 2008, when Croatia imported goods and services from 180 countries worldwide, whereas the lowest value was recorded in 2017, when 127 countries exported their goods and services to Croatia. The trend of increasing import values while the number of importing countries decreased resulted in the fact that the highest average import value per importing country was recorded in the most recent period, in 2018. In Table 2, the distribution of import partners of Croatia according to the distance between the capitals is shown.

Table 2. The distribution of import partners of Croatia according to the distance between the capitals, in the period from 2001 to 2018

\begin{tabular}{ccccc}
\hline Year & \multicolumn{5}{c}{ Distance between capitals } \\
\cline { 2 - 6 } & $\begin{array}{c}\text { Less than } \\
\mathbf{1 , 0 0 0} \mathbf{~ k m}\end{array}$ & $\begin{array}{c}\text { Between 1,000 and } \\
\mathbf{3 , 0 0 0} \mathbf{~ k m}\end{array}$ & $\begin{array}{c}\text { Between 3,000 and } \\
\mathbf{5 , 0 0 0} \mathbf{~ k m}\end{array}$ & $\begin{array}{c}\text { More than 5,000 } \\
\mathbf{~ k m}\end{array}$ \\
\hline 2001 & 15 & 34 & 29 & 79 \\
\hline 2002 & 15 & 34 & 32 & 78 \\
\hline 2003 & 15 & 35 & 32 & 84 \\
\hline 2004 & 15 & 36 & 36 & 86 \\
\hline 2005 & 15 & 35 & 33 & 84 \\
\hline 2006 & 15 & 35 & 36 & 87 \\
\hline 2007 & 15 & 36 & 34 & 85 \\
\hline 2008 & 15 & 35 & 35 & 95 \\
\hline 2009 & 15 & 35 & 35 & 90 \\
\hline 2010 & 15 & 35 & 33 & 85 \\
\hline 2011 & 15 & 35 & 31 & 70 \\
\hline 2012 & 15 & 34 & 34 & 67 \\
\hline 2013 & 16 & 34 & 24 & 65 \\
\hline 2014 & 15 & 34 & 24 & 66 \\
\hline 2015 & 15 & 34 & 22 & 60 \\
\hline 2016 & 15 & 34 & 24 & 65 \\
\hline 2017 & 15 & 34 & 18 & \\
\hline 2018 & 15 & 34 & 23 & \\
\hline
\end{tabular}

Source: Authors' calculations 
Distances between countries are divided into three categories: less than 1,000 $\mathrm{km}$, between 1,000 and 3,000 km, between 3,000 and 5,000 km and more than 5,000 $\mathrm{km}$. This division was made in order to capture the distance effect which is present in smaller distances and analyse whether the precision of the Distance variable will change across its distribution. The assumption is that the Distance variable should perform better in case of smaller distances.

Data in Table 2 leads to the conclusion that the number of countries from which Croatia imports goods and services is almost constant in case of smaller distances (less than $1,000 \mathrm{~km}$ and between 1,000 and 3,000 $\mathrm{km}$ categories). However, in the case of larger distances, in categories between 3,000 and 5,000 km and more than $5,000 \mathrm{~km}$, the number of importing countries differs greatly in the observed period.

\subsection{The sign test results}

The results of conducted sign tests for the GDP and Distance variables are displayed in Table 3. For comparison purposes, in addition to the sign test results related to the World, in Table 3 the sign test results related to the Central and Eastern European countries (CEEC), European Union (EU) and one individual country, Croatia, are provided. It has to be emphasized that the category the World does not include all countries in the World. The World category includes 174 countries throughout the observed period. Due to the lack of available data, the World category includes 153 countries per year on average, which is a great amount of bilateral trade data in the observed period. For example, the dataset for the calculation of the sign test for the World countries comprises of 363,405 entries on bilateral trade data for the selected countries in the World. According to OECD, OECD (2019), the member countries of Central and Eastern European countries (CEE) are Albania, Bulgaria, Croatia, the Czech Republic, Estonia, Hungary, Latvia, Lithuania, Poland, Romania, the Slovak Republic and Slovenia. Because of missing data for Romania, here the CEE group of countries is not composed of 12 but of 11 countries. Similarly, because there are no available data for Greece and Romania, the group of EU member states here is composed of 26 instead of 28 countries.

The results of the sign test shown in Table 3 elicit the conclusion that there is almost $90 \%$ of positive signs achieved for the GDP variable in the case of Croatia, the EU countries, CEEC and all countries in the World which is a highly expected result. It means that the GDP variable possesses a high predictive capability or performance in the sign test. A country will import more from countries with GDP higher than average World GDP and vice versa. On the other hand, the Distance variable did not perform so well in the sign test. It correctly predicted bilateral trade patterns in only $52 \%$ of cases for the World, which is only a little more than a coin toss or random value. 
Table 3. The sign test results for the GDP and Distance variables, the World, the CEE countries, the European Union (EU) member states and Croatia, in the period from 2001 to 2018

\begin{tabular}{ccccccccc}
\hline \multirow{2}{*}{ Year } & \multicolumn{2}{c}{ World } & \multicolumn{2}{c}{ CEE } & \multicolumn{2}{c}{ EU } & \multicolumn{2}{c}{ Croatia } \\
\cline { 2 - 8 } & GDP & Distance & GDP & Distance & GDP & Distance & GDP & Distance \\
\hline 2001 & $88 \%$ & $53 \%$ & $89 \%$ & $57 \%$ & $91 \%$ & $55 \%$ & $90 \%$ & $55 \%$ \\
\hline 2002 & $89 \%$ & $53 \%$ & $90 \%$ & $57 \%$ & $91 \%$ & $55 \%$ & $92 \%$ & $55 \%$ \\
\hline 2003 & $89 \%$ & $53 \%$ & $90 \%$ & $56 \%$ & $92 \%$ & $55 \%$ & $92 \%$ & $54 \%$ \\
\hline 2004 & $88 \%$ & $53 \%$ & $90 \%$ & $56 \%$ & $91 \%$ & $55 \%$ & $91 \%$ & $54 \%$ \\
\hline 2005 & $88 \%$ & $52 \%$ & $90 \%$ & $56 \%$ & $91 \%$ & $55 \%$ & $91 \%$ & $54 \%$ \\
\hline 2006 & $88 \%$ & $53 \%$ & $90 \%$ & $56 \%$ & $91 \%$ & $56 \%$ & $91 \%$ & $53 \%$ \\
\hline 2007 & $88 \%$ & $52 \%$ & $89 \%$ & $56 \%$ & $91 \%$ & $55 \%$ & $90 \%$ & $54 \%$ \\
\hline 2008 & $87 \%$ & $52 \%$ & $89 \%$ & $57 \%$ & $90 \%$ & $56 \%$ & $91 \%$ & $56 \%$ \\
\hline 2009 & $87 \%$ & $52 \%$ & $89 \%$ & $57 \%$ & $90 \%$ & $55 \%$ & $91 \%$ & $55 \%$ \\
\hline 2010 & $87 \%$ & $52 \%$ & $87 \%$ & $57 \%$ & $89 \%$ & $56 \%$ & $90 \%$ & $56 \%$ \\
\hline 2011 & $87 \%$ & $52 \%$ & $87 \%$ & $57 \%$ & $89 \%$ & $56 \%$ & $89 \%$ & $57 \%$ \\
\hline 2012 & $87 \%$ & $52 \%$ & $87 \%$ & $56 \%$ & $89 \%$ & $56 \%$ & $90 \%$ & $55 \%$ \\
\hline 2013 & $88 \%$ & $52 \%$ & $87 \%$ & $57 \%$ & $89 \%$ & $56 \%$ & $85 \%$ & $60 \%$ \\
\hline 2014 & $87 \%$ & $52 \%$ & $87 \%$ & $56 \%$ & $89 \%$ & $56 \%$ & $86 \%$ & $56 \%$ \\
\hline 2015 & $88 \%$ & $52 \%$ & $86 \%$ & $56 \%$ & $89 \%$ & $55 \%$ & $85 \%$ & $58 \%$ \\
\hline 2016 & $88 \%$ & $52 \%$ & $86 \%$ & $57 \%$ & $89 \%$ & $55 \%$ & $86 \%$ & $59 \%$ \\
\hline 2017 & $88 \%$ & $52 \%$ & $86 \%$ & $57 \%$ & $89 \%$ & $56 \%$ & $83 \%$ & $59 \%$ \\
\hline 2018 & $89 \%$ & $52 \%$ & $87 \%$ & $57 \%$ & $89 \%$ & $55 \%$ & $86 \%$ & $59 \%$ \\
\hline
\end{tabular}

Source: Authors' calculations

This can be explained by the globalisation of World trade in recent years. However, for the EU, CEEC and Croatia, this percentage is somewhat higher and is in the range of $55 \%$ to $60 \%$. In Table 4, we wanted to see whether the distribution of signs of the GDP and Distance variables changes if bilateral trade distance is divided into different categories.

The results for Croatia indicate that the distribution of signs for the GDP variable is quite low for the distances less than $1,000 \mathrm{~km}$. This can be explained by intraregional trade and extensive trade with neighbouring countries. In contrast, the Distance variable performed best both for smaller and larger distances. This result is very similar to the one obtained for the EU, CEEC and all countries worldwide displayed in Tables A1-A3 in the Appendix. It can be concluded that the GDP variable had higher distribution of positive signs for larger distances while the Distance variable had higher distribution of positive signs for smaller distances and distances over $5,000 \mathrm{~km}$.

In Figure 1, the sign test results for the GDP variable for Croatia in the year 2018 are shown in more detail. In order to compose Figure 1, countries that imported their goods to Croatia in 2018 were sorted in increasing order according to their GDP 
values. Therefore, at the beginning of the list are countries with lower GDP values and at the end of the list are countries with higher GDP values. In the next step, for each country individually it was checked whether the resulting sign is equal or not to the expected one. After that the cumulative function of correct signs was calculated and shown in Figure 1 by the black line. The orange line represents the perfect line. The cumulative function of correct signs and the orange line ought to be one on top of one another if all signs are correct. The less correct the results of the sign test are, as we move towards the right of the Figure 1, the difference between those two lines is greater.

Table 4. The sign test results for the GDP and Distance variables for Croatia according to distance between capitals, in the period from 2001 to 2018

\begin{tabular}{|c|c|c|c|c|c|c|c|c|}
\hline \multirow[b]{2}{*}{ Year } & \multicolumn{4}{|c|}{ GDP } & \multicolumn{4}{|c|}{ Distance } \\
\hline & $\begin{array}{c}\text { Less } \\
\text { than } \\
1,000 \\
\text { km }\end{array}$ & $\begin{array}{l}\text { Between } \\
1,000 \text { and } \\
3,000 \mathrm{~km}\end{array}$ & $\begin{array}{c}\text { Between } \\
3,000 \text { and } \\
5,000 \mathrm{~km}\end{array}$ & $\begin{array}{c}\text { More } \\
\text { than } \\
5,000 \\
\text { km }\end{array}$ & $\begin{array}{c}\text { Less } \\
\text { than } \\
1,000 \\
\text { km }\end{array}$ & $\begin{array}{l}\text { Between } \\
1,000 \text { and } \\
3,000 \mathrm{~km}\end{array}$ & $\begin{array}{c}\text { Between } \\
3,000 \text { and } \\
5,000 \mathrm{~km}\end{array}$ & $\begin{array}{c}\text { More } \\
\text { than } \\
\mathbf{5 , 0 0 0} \\
\mathbf{~ k m}\end{array}$ \\
\hline 2001 & $53 \%$ & $91 \%$ & $100 \%$ & $94 \%$ & $67 \%$ & $29 \%$ & $0 \%$ & $84 \%$ \\
\hline 2002 & $53 \%$ & $94 \%$ & $100 \%$ & $95 \%$ & $73 \%$ & $29 \%$ & $0 \%$ & $86 \%$ \\
\hline 2003 & $60 \%$ & $91 \%$ & $100 \%$ & $94 \%$ & $67 \%$ & $29 \%$ & $0 \%$ & $83 \%$ \\
\hline 2004 & $60 \%$ & $92 \%$ & $97 \%$ & $94 \%$ & $73 \%$ & $31 \%$ & $0 \%$ & $84 \%$ \\
\hline 2005 & $53 \%$ & $94 \%$ & $97 \%$ & $94 \%$ & $80 \%$ & $26 \%$ & $0 \%$ & $83 \%$ \\
\hline 2006 & $53 \%$ & $94 \%$ & $97 \%$ & $94 \%$ & $80 \%$ & $26 \%$ & $0 \%$ & $82 \%$ \\
\hline 2007 & $53 \%$ & $92 \%$ & $94 \%$ & $94 \%$ & $80 \%$ & $28 \%$ & $0 \%$ & $82 \%$ \\
\hline 2008 & $53 \%$ & $97 \%$ & $94 \%$ & $94 \%$ & $80 \%$ & $29 \%$ & $0 \%$ & $83 \%$ \\
\hline 2009 & $60 \%$ & $91 \%$ & $94 \%$ & $94 \%$ & $73 \%$ & $29 \%$ & $0 \%$ & $84 \%$ \\
\hline 2010 & $60 \%$ & $91 \%$ & $94 \%$ & $92 \%$ & $73 \%$ & $29 \%$ & $0 \%$ & $84 \%$ \\
\hline 2011 & $53 \%$ & $91 \%$ & $90 \%$ & $93 \%$ & $80 \%$ & $29 \%$ & $0 \%$ & $84 \%$ \\
\hline 2012 & $60 \%$ & $91 \%$ & $91 \%$ & $94 \%$ & $67 \%$ & $29 \%$ & $0 \%$ & $85 \%$ \\
\hline 2013 & $63 \%$ & $88 \%$ & $88 \%$ & $87 \%$ & $63 \%$ & $32 \%$ & $4 \%$ & $93 \%$ \\
\hline 2014 & $60 \%$ & $91 \%$ & $92 \%$ & $88 \%$ & $67 \%$ & $24 \%$ & $0 \%$ & $90 \%$ \\
\hline 2015 & $53 \%$ & $91 \%$ & $95 \%$ & $86 \%$ & $67 \%$ & $26 \%$ & $0 \%$ & $92 \%$ \\
\hline 2016 & $47 \%$ & $91 \%$ & $96 \%$ & $88 \%$ & $73 \%$ & $26 \%$ & $0 \%$ & $94 \%$ \\
\hline 2017 & $53 \%$ & $88 \%$ & $94 \%$ & $85 \%$ & $67 \%$ & $29 \%$ & $0 \%$ & $92 \%$ \\
\hline 2018 & $47 \%$ & $91 \%$ & $96 \%$ & $89 \%$ & $73 \%$ & $26 \%$ & $0 \%$ & $94 \%$ \\
\hline
\end{tabular}

Source: Authors' calculations

The results from the Figure 1 indicate that the GDP variable had higher distribution of positive signs in case of Croatian bilateral imports with countries having the lowest gross domestic product (for the first 50 smallest trade partner countries there was only one incorrect sign in the sign test). The elements for construction of Figure 2 are calculated in the same way as for Figure 1, but now using data for the Distance variable instead of the GDP variable. The Distance variable had higher distribution of positive signs for small and larger distances, the result already seen in Table 4. 
Figure 1. The sign test results for the GDP variable for Croatia according to the GDP value of exporter countries, in 2018

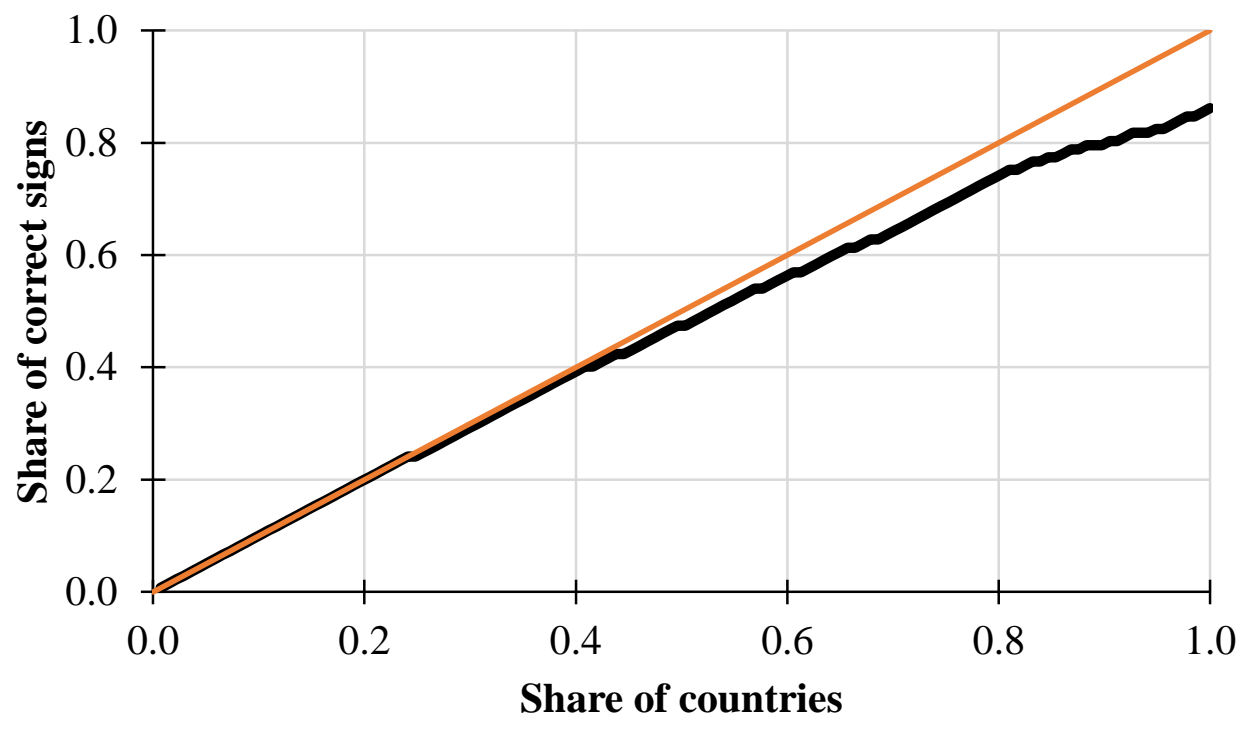

Source: Authors' representation

Figure 2. The sign test results for the Distance variable for Croatia according to the Distance value of exporter countries, in 2018

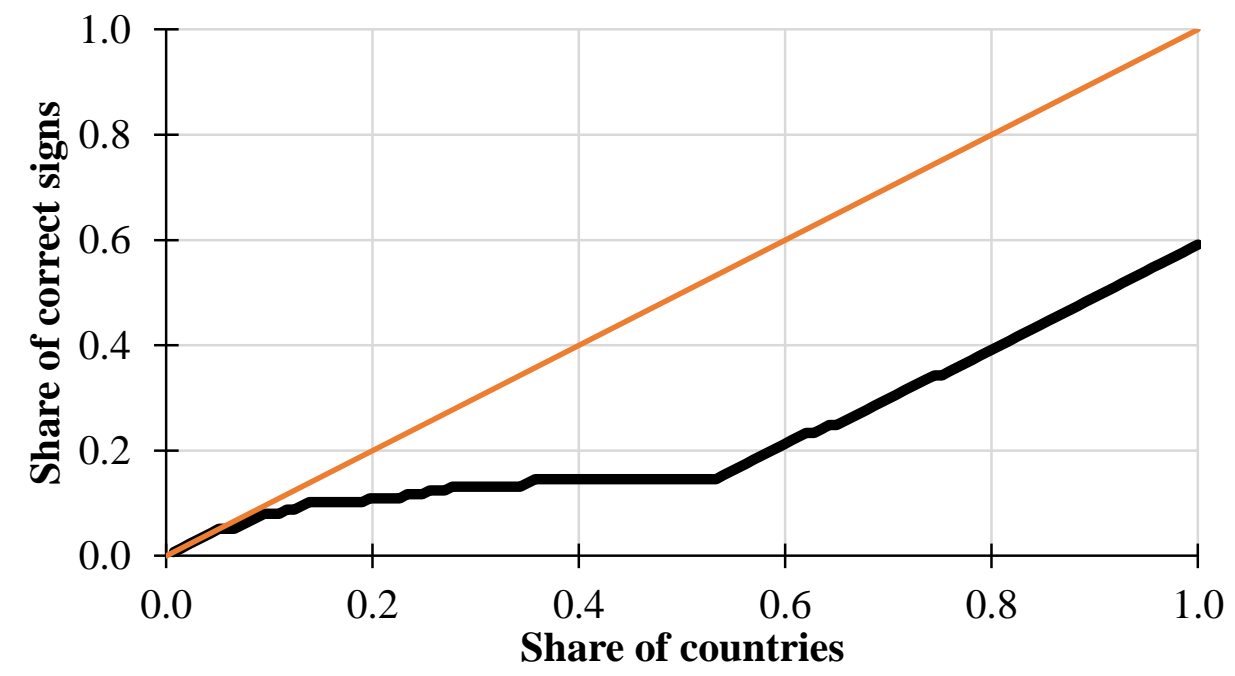

Source: Authors' representation 
In Figures A1 and A2, in the Appendix, the sign test results are observed in more detail than in Figures 1 and 2. The importing countries were firstly split into four groups according to their distance between capitals. The analysis was then conducted similarly as in Figures 1 and 2, for each distance group separately. Again, the results are very similar to the ones in Table 4; the GDP variable had higher distribution of positive signs for distances higher than 1,000 km. Furthermore, the Distance variable had higher distribution of positive signs for distances less than $1,000 \mathrm{~km}$ and distances more than $5,000 \mathrm{~km}$.

\subsection{The rank test results}

In Tables 5 and 6 the average root mean square errors and average mean absolute percentage errors for the GDP and Distance variables in the case of the World, the CEE countries, the European Union (EU) member states and Croatia are shown. It has to be emphasized that the average error values have been calculated by summing up individual error values of importing countries from the same country group and by dividing that sum with the number of importing countries.

Table 5. The rank test errors for the GDP variable, the World, the CEEC, the European Union (EU) member states and Croatia, average by country, in the period from 2001 to 2018

\begin{tabular}{ccccccccc}
\hline \multirow{2}{*}{ Year } & \multicolumn{2}{c}{ World } & \multicolumn{2}{c}{ CEE } & \multicolumn{2}{c}{ EU } & \multicolumn{2}{c}{ Croatia } \\
\cline { 2 - 9 } & RMSE & MAPE & RMSE & MAPE & RMSE & MAPE & RMSE & MAPE \\
\hline 2001 & 27 & $70 \%$ & 30 & $63 \%$ & 29 & $48 \%$ & 33 & $67 \%$ \\
\hline 2002 & 27 & $70 \%$ & 29 & $61 \%$ & 28 & $47 \%$ & 30 & $63 \%$ \\
\hline 2003 & 27 & $70 \%$ & 29 & $60 \%$ & 28 & $46 \%$ & 31 & $59 \%$ \\
\hline 2004 & 28 & $71 \%$ & 31 & $62 \%$ & 29 & $48 \%$ & 30 & $56 \%$ \\
\hline 2005 & 28 & $73 \%$ & 32 & $62 \%$ & 30 & $49 \%$ & 31 & $60 \%$ \\
\hline 2006 & 28 & $70 \%$ & 32 & $61 \%$ & 29 & $48 \%$ & 33 & $60 \%$ \\
\hline 2007 & 28 & $69 \%$ & 31 & $60 \%$ & 29 & $48 \%$ & 31 & $57 \%$ \\
\hline 2008 & 29 & $69 \%$ & 31 & $61 \%$ & 29 & $49 \%$ & 32 & $56 \%$ \\
\hline 2009 & 29 & $68 \%$ & 30 & $64 \%$ & 29 & $51 \%$ & 30 & $57 \%$ \\
\hline 2010 & 29 & $68 \%$ & 31 & $69 \%$ & 30 & $54 \%$ & 30 & $63 \%$ \\
\hline 2011 & 29 & $69 \%$ & 32 & $69 \%$ & 30 & $55 \%$ & 32 & $64 \%$ \\
\hline 2012 & 29 & $69 \%$ & 32 & $72 \%$ & 30 & $57 \%$ & 32 & $67 \%$ \\
\hline 2013 & 30 & $69 \%$ & 32 & $73 \%$ & 30 & $58 \%$ & 30 & $87 \%$ \\
\hline 2014 & 30 & $69 \%$ & 32 & $78 \%$ & 30 & $59 \%$ & 30 & $86 \%$ \\
\hline 2015 & 29 & $67 \%$ & 31 & $81 \%$ & 30 & $61 \%$ & 30 & $91 \%$ \\
\hline 2016 & 29 & $66 \%$ & 31 & $78 \%$ & 30 & $59 \%$ & 31 & $88 \%$ \\
\hline 2017 & 29 & $66 \%$ & 31 & $79 \%$ & 30 & $61 \%$ & 30 & $96 \%$ \\
\hline 2018 & 28 & $63 \%$ & 29 & $74 \%$ & 28 & $58 \%$ & 29 & $88 \%$ \\
\hline
\end{tabular}

Source: Authors' calculations 
Obviously, there was no need to calculate average errors in the described way in the case when only Croatia was observed. The results from Tables 5 and 6 indicate that both the RMSE and MAPE are higher for the Distance variable than for the GDP variable. It means that the GDP variable can better predict bilateral trade patterns in the gravity model than the Distance variable.

The exception is the case of Croatia where the MAPE for the Distance variable was lower than the MAPE for the GDP variable after the year 2013, meaning that the Distance variable was more precise in that interval in explaining bilateral trade imports than the GDP variable. However, overall forecasting or predicting accuracy for both GDP and Distance variables can be interpreted as poor.

Table 6. Rank test errors for the Distance variable, World, the CEEC, the European Union (EU) member states and Croatia, average by country, in period from 2001 to 2018

\begin{tabular}{ccccccccc}
\hline \multirow{2}{*}{ Year } & \multicolumn{2}{c}{ World } & \multicolumn{2}{c}{ CEE } & \multicolumn{2}{c}{ EU } & \multicolumn{2}{c}{ Croatia } \\
\cline { 2 - 9 } & RMSE & MAPE & RMSE & MAPE & RMSE & MAPE & RMSE & MAPE \\
\hline 2001 & 47 & $149 \%$ & 47 & $98 \%$ & 55 & $115 \%$ & 51 & $93 \%$ \\
\hline 2002 & 48 & $148 \%$ & 48 & $99 \%$ & 55 & $111 \%$ & 51 & $96 \%$ \\
\hline 2003 & 48 & $146 \%$ & 48 & $99 \%$ & 55 & $111 \%$ & 53 & $93 \%$ \\
\hline 2004 & 49 & $146 \%$ & 50 & $96 \%$ & 56 & $109 \%$ & 57 & $98 \%$ \\
\hline 2005 & 50 & $147 \%$ & 51 & $99 \%$ & 56 & $110 \%$ & 55 & $98 \%$ \\
\hline 2006 & 51 & $150 \%$ & 50 & $99 \%$ & 56 & $110 \%$ & 57 & $97 \%$ \\
\hline 2007 & 51 & $154 \%$ & 51 & $102 \%$ & 56 & $111 \%$ & 56 & $102 \%$ \\
\hline 2008 & 51 & $155 \%$ & 50 & $101 \%$ & 56 & $110 \%$ & 56 & $97 \%$ \\
\hline 2009 & 51 & $156 \%$ & 50 & $103 \%$ & 56 & $112 \%$ & 57 & $102 \%$ \\
\hline 2010 & 51 & $157 \%$ & 48 & $101 \%$ & 55 & $113 \%$ & 53 & $99 \%$ \\
\hline 2011 & 52 & $155 \%$ & 49 & $100 \%$ & 55 & $111 \%$ & 53 & $99 \%$ \\
\hline 2012 & 51 & $156 \%$ & 49 & $99 \%$ & 55 & $110 \%$ & 54 & $100 \%$ \\
\hline 2013 & 52 & $159 \%$ & 48 & $98 \%$ & 55 & $110 \%$ & 43 & $80 \%$ \\
\hline 2014 & 52 & $159 \%$ & 44 & $92 \%$ & 53 & $108 \%$ & 41 & $77 \%$ \\
\hline 2015 & 52 & $161 \%$ & 44 & $94 \%$ & 54 & $111 \%$ & 40 & $79 \%$ \\
\hline 2016 & 52 & $163 \%$ & 44 & $93 \%$ & 53 & $111 \%$ & 40 & $79 \%$ \\
\hline 2017 & 53 & $164 \%$ & 44 & $92 \%$ & 53 & $110 \%$ & 37 & $78 \%$ \\
\hline 2018 & 52 & $157 \%$ & 43 & $94 \%$ & 51 & $109 \%$ & 39 & $75 \%$ \\
\hline
\end{tabular}

Source: Authors' calculations

\subsection{Regression analysis}

Due to a different number of countries included in the observed country group, a different number of regression models was estimated. In the case of the World, overall 2,760 standardized multiple linear regression models were estimated (with approximately 153 regression models per year). Eleven Central and Eastern 
European (CEE) countries were included with 198 standardized multiple linear regression models estimated. Overall, 26 European Union (EU) member states were included in the analysis with 468 standardized multiple linear regression models estimated, while for Croatia there were 18 standardised multiple linear regression models. In Table 7, the statistical significance of standardized GDP and Distance variables as well as 2,760 multiple linear regression models at $1 \%$ and $5 \%$ of significance for the all countries in the World are presented.

Table 7. The statistical significance of standardised variables and regression models, World

\begin{tabular}{|c|c|c|c|c|}
\hline $\begin{array}{l}\text { Variable/regression } \\
\text { model, significance }\end{array}$ & Total & Yes & No & $\begin{array}{c}\% \text { of } \\
\text { significant } \\
\text { cases }\end{array}$ \\
\hline zGDP, significant at 5\% & 2,760 & 2,412 & 348 & $87.39 \%$ \\
\hline $\mathrm{zGDP}$, significant at $1 \%$ & 2,760 & 2,273 & 487 & 82.36 \\
\hline $\begin{array}{l}\text { zDistance, significant at } \\
5 \%\end{array}$ & 2,760 & 2,004 & 756 & $72.61 \%$ \\
\hline $\begin{array}{l}\text { zDistance, significant at } \\
1 \%\end{array}$ & 2760 & 1,484 & 1276 & $53.77 \%$ \\
\hline $\begin{array}{l}\text { Regression model, } \\
\text { significant at } 5 \%\end{array}$ & 2,760 & 2,531 & 229 & $91.70 \%$ \\
\hline $\begin{array}{l}\text { Regression model, } \\
\text { significant at } 1 \%\end{array}$ & 2,760 & 2,372 & 388 & $85.94 \%$ \\
\hline
\end{tabular}

Source: Authors' calculations

It can be noticed that the standardized GDP variable is significant in $87.39 \%$ of cases, the significance level being less $5 \%$ and in $82.36 \%$ of cases the significance level being less than $1 \%$. On the other hand, the standardized Distance variable is significant in lower percentage of cases than the standardized GDP variable (the significance level less than $5 \%$ in $72.61 \%$ of cases and the significance level less than $1 \%$ in $53.77 \%$ of cases). This result further favours the GDP variable over the Distance variable as the more significant variable in the standard gravity regression model. A more detailed multiple linear regression analysis is shown in Table A4 for Croatia only, although the analysis was made for all countries worldwide but due to paper restrictions it was not possible to show it all. The detailed analysis includes regression results for beta zGDP and beta zDistance variables with associated standard errors, $p$-values and t-statistics. In addition, data for calculated regression $p$ and F-values, the degrees of freedom and the coefficient of determination are presented in Table 4. In Table 8 the percentages of cases in which the GDP or Distance variable had the higher impact on the Imports variable are shown. 
Table 8. The impact of the GDP and Distance variables in the gravity regression model, the World, the CEEC, EU member states and Croatia, in the period from 2001 to 2018

\begin{tabular}{|c|c|c|c|c|c|c|c|c|}
\hline \multirow[t]{2}{*}{ Year } & \multicolumn{2}{|c|}{ World } & \multicolumn{2}{|c|}{ CEE } & \multicolumn{2}{|c|}{$\mathrm{EU}$} & \multicolumn{2}{|c|}{ Croatia } \\
\hline & GDP & Distance & GDP & Distance & GDP & Distance & GDP & Distance \\
\hline 2001 & $79 \%$ & $21 \%$ & $64 \%$ & $36 \%$ & $88 \%$ & $12 \%$ & $100 \%$ & $0 \%$ \\
\hline 2002 & $79 \%$ & $21 \%$ & $64 \%$ & $36 \%$ & $88 \%$ & $12 \%$ & $100 \%$ & $0 \%$ \\
\hline 2003 & $77 \%$ & $23 \%$ & $73 \%$ & $27 \%$ & $88 \%$ & $12 \%$ & $100 \%$ & $0 \%$ \\
\hline 2004 & $81 \%$ & $19 \%$ & $64 \%$ & $36 \%$ & $88 \%$ & $12 \%$ & $100 \%$ & $0 \%$ \\
\hline 2005 & $81 \%$ & $19 \%$ & $64 \%$ & $36 \%$ & $88 \%$ & $12 \%$ & $100 \%$ & $0 \%$ \\
\hline 2006 & $78 \%$ & $22 \%$ & $64 \%$ & $36 \%$ & $85 \%$ & $15 \%$ & $100 \%$ & $0 \%$ \\
\hline 2007 & $81 \%$ & $19 \%$ & $64 \%$ & $36 \%$ & $88 \%$ & $12 \%$ & $100 \%$ & $0 \%$ \\
\hline 2008 & $85 \%$ & $15 \%$ & $73 \%$ & $27 \%$ & $88 \%$ & $12 \%$ & $100 \%$ & $0 \%$ \\
\hline 2009 & $83 \%$ & $17 \%$ & $73 \%$ & $27 \%$ & $88 \%$ & $12 \%$ & $100 \%$ & $0 \%$ \\
\hline 2010 & $82 \%$ & $18 \%$ & $64 \%$ & $36 \%$ & $85 \%$ & $15 \%$ & $100 \%$ & $0 \%$ \\
\hline 2011 & $83 \%$ & $17 \%$ & $64 \%$ & $36 \%$ & $81 \%$ & $19 \%$ & $100 \%$ & $0 \%$ \\
\hline 2012 & $88 \%$ & $12 \%$ & $64 \%$ & $36 \%$ & $85 \%$ & $15 \%$ & $100 \%$ & $0 \%$ \\
\hline 2013 & $85 \%$ & $15 \%$ & $55 \%$ & $45 \%$ & $73 \%$ & $27 \%$ & $0 \%$ & $100 \%$ \\
\hline 2014 & $85 \%$ & $15 \%$ & $36 \%$ & $64 \%$ & $69 \%$ & $31 \%$ & $0 \%$ & $100 \%$ \\
\hline 2015 & $85 \%$ & $15 \%$ & $36 \%$ & $64 \%$ & $65 \%$ & $35 \%$ & $0 \%$ & $100 \%$ \\
\hline 2016 & $84 \%$ & $16 \%$ & $36 \%$ & $64 \%$ & $65 \%$ & $35 \%$ & $0 \%$ & $100 \%$ \\
\hline 2017 & $85 \%$ & $15 \%$ & $36 \%$ & $64 \%$ & $65 \%$ & $35 \%$ & $0 \%$ & $100 \%$ \\
\hline 2018 & $85 \%$ & $15 \%$ & $45 \%$ & $55 \%$ & $73 \%$ & $27 \%$ & $0 \%$ & $100 \%$ \\
\hline
\end{tabular}

Source: Authors' calculations

It can be noticed that the GDP variable had higher impact on the Imports variable than the Distance variable in approximately $80 \%$ of cases for all countries in the World (in 2018 this percentage was somewhat higher and amounted to 85\%). For other subsample of countries, the CEE, the EU, and Croatia individually the results are similar; the GDP variable had higher impact in the majority of regression models. This analysis has provided new insight into understanding the performance of GDP and Distance variables in the standard gravity model. Both the GDP and Distance variables have been considered as the main variables in the standard gravity model of trade with numerous papers estimating their regression coefficients. But regression analysis itself could not get into the core of understanding the performance and impact of variables in the gravity model, which was the idea of this paper. It seems that the economic size of a country, represented with the GDP value, is more important factor than the distance between countries in making a decision with which country to trade. This is the main finding of this paper offering an important advantage over the parametric tests of the gravity model. 


\section{Conclusion}

The aforementioned analysis offers the conclusion that the GDP variable had positive distribution of signs for bilateral trade patterns (imports) for Croatia, the EU countries, the CEEC and all countries worldwide in almost 90\% of cases, which is a very convincing and highly expected result. On the other hand, the Distance variable had lower positive distribution of signs on the sign test, only $52 \%$ of cases for the countries worldwide which is barely more than a coin toss. The low percentage of correct signs achieved in the sign test for the Distance variable means that making decisions about which country to trade with is not conditioned on bilateral distance between countries. For the EU, the CEEC and Croatia, this percentage is somewhat higher and is in the range of 55\% to $60 \%$. When bilateral distances were divided into different categories, the GDP variable performed best for larger distances, while the Distance variable was the most precise for smaller distances. Therefore, the first hypothesis of the paper could be partially confirmed. The results of the rank test for both the RMSE and MAPE metrics were both higher for the Distance variable than for the GDP variable, meaning that GDP variable performs better in the gravity model than the Distance variable. However, overall forecasting performance for both GDP and Distance variables can be interpreted as poor. This result further favours the GDP variable as the more significant variable in the standard gravity regression model. Furthermore, the GDP variable had higher impact on the dependent variable in approximately $80 \%$ of cases when multiple linear regression models with standardised variables were estimated, indicating that second hypothesis of the paper could be confirmed. This result further favours the GDP variable as the more important variable in the gravity model, meaning that patterns of trade are more dependent on the economic size of countries than their bilateral distance. The results of the sign and rank tests for Croatia are in line with the results obtained for the CEE and the EU countries. The GDP variable had higher distribution of positive signs than the Distance variable. Furthermore, the GDP variable had higher distribution of positive signs for smaller distances while the Distance variable had higher positive distribution of signs for smaller and larger distances. In the regression analysis for Croatia the GDP variable had also higher impact but only up to the year 2013, after which the Distance variable had higher impact. In order to understand that result, a more detailed analysis should be made. The reasons for this may be the Croatia's accession to the EU in 2013, larger intra-EU trade, yearly changes in countries' GDP values, etc.

The limitations of the paper are the result of the missing data for some countries in some years, so the sample of countries had to be selected. Therefore, only $11 \mathrm{CEEC}$ and $26 \mathrm{EU}$ countries were included in the analysis. Also, due to paper length restrictions, a detailed analysis for all World countries individually could not be shown. Further investigations in this field should be made by analysing trade flows other than imports, countries according to their income level, implementing various distance indicators, etc. As far as the methodology used for calculating of 
the sign test, an interesting possibility would be to use the mode or median value as anchor value instead of using the mean value.

\section{References}

Almog, A., Bird, R. and Garlaschelli, D. (2019), Enhanced Gravity Model of Trade: Reconciling Macroeconomic and Network Models, Frontiers in Physics, 7(55), pp. 1 17. https://doi.org/10.3389/fphy.2019.00055

Anderson, J.E. (1979), A theoretical foundation for the gravity equation, American Economic Review, 69(1), pp. io6-i6.

Anderson, J.E. and Van Wincoop, E. (2003), Gravity with gravitas: A solution to the border puzzle, American Economic Review, 93(1), pp. 170-192. https://doi.org/10.1257/000282803321455214

Baldwin, R. and Taglioni, D. (2007), Trade Effects of the Euro: a Comparison of Estimators, Journal of Economic Integration, 22(4), pp. 780-818. https://doi.org/10.11130/jei.2007.22.4.780

Bergstrand, J.H. (1985), The Gravity Equation in International Trade: Some Microeconomic Foundations and Empirical Evidence, Review of Economics and Statistics, 67(3), pp. 474-81. https://doi.org/10.2307/1925976

Chaney, T. (2014), The Gravity Equation in International Trade: An Explanation (retrieved from http://www8.gsb.columbia.edu/programs-admissions/sites/programs-admissions/ files/finance/Macro\%20Workshop/spring\%202014/Thomas\%20Chaney.pdf).

De Benedictis, L. and Taglioni, D. (2011), The Gravity Model in International Trade, in: De Benedictis, L. and Saltici, L. (ed.), The Trade Impact of European Union Preferencial Policies, Springer.

Deardorff, A.V. (1998), Determinants of Bilateral Trade: Does Gravity Work in a Neoclassical World? in: Frankel, J.A. (ed.), The Regionalization of the World Economy, Chicago: University of Chicago Press.

Disdier, A.-C. and Head, K. (2008), The Puzzling Persistence of the Distance Effect on Bilateral Trade, Review of Economics and Statistics, 90(1), pp. 37-48. https://doi.org/10.1162/rest.90.1.37

Eaton, J. and Kortum, S. (2002), Technology, Geography, and Trade, Econometrica, 70(5), pp. 1741-1779. https://doi.org/10.1111/1468-0262.00352

Heckman, J. (1979), Sample Selection Bias as a Specification Error, Econometrica, (47), pp. 153-161.

Helpman, E., Melitz, M.J. and Rubinstein, Y. (2008), Estimating Trade Flows: Trading Partners and Trading Volumes, Quarterly Journal of Economics, 123(2), pp. 441-487. http://dx.doi.org/10.1162/qjec.2008.123.2.441

Kareem, F.O. and Kareem, O.I. (2014), Specification and Estimation of Gravity Models: A Review of the Issues in the Literature, EUI Working Paper RSCAS 2014/74 (retrieved from https://ideas.repec.org/p/rsc/rsceui/2014-74.html). 
Kohler, W.K. (1991), How Robust Are Sign and Rank Order Tests of the Heckscher-OhlinVanek Theorem?, Research seminar in international economics, Seminar Disscusion paper No. 212 (retrieved from https://ideas.repec.org/p/mie/wpaper/212.html).

Konstantinos, K., Karlaftis, M.G. and Tsamboulas, D. (2010), The Gravity Model Specification for Modeling International Trade Flows and Free Trade Agreement Effects: A 10-Year Review of Empirical Studies, The Open Economics Journal, 3(1), pp. 1-13. http://dx.doi.org/10.2174/1874919401003010001

Kreinovich, V. and Sriboonchitta, S. (2017), Quantitative Justification for the Gravity Model in Economics, Departmental Technical Reports (CS). 1147 (retrieved from http://digitalcommons.utep.edu/cs_techrep/1147).

Krugman, P. (1980), Scale Economies, Product Differentiation, and the Pattern of Trade, American Economic Review, 70(5), pp. 950-959.

Lewis, C.D. (1982), Industrial and Business Forecasting Methods, Butterworths Publishing, London, 40.

Mayer, T. and Zignago, S. (2006), Notes on CEPII's Distances Measures, mimeo (retrieved from http://www.cepii.fr/CEPII/en/publications/wp/abstract.asp?NoDoc=3877).

McCallum, J. (1995), National Borders Matter: Canada-U.S. Regional Trade Patterns, American Economic Review, 85(3), pp. 615-623.

OECD (2019), Glossary of statistical terms. CEE countries (retrieved from https://stats.oecd.org/glossary/detail.asp?ID=303).

Ohlin, B. (1933), Interregional and International Trade, Cambridge, Mass.: Harvard University Press, 1966.

Poissonnier, A. (2016), Solving for Structural Gravity in Panels: Yes We Can, European Commission, Discussion Paper 040, December 2016 (retrieved from http://ec.europa.eu/economy_finance/publications).

Salvatici, L. (2013), The Gravity Model in International Trade, AGRODEP Technical Note TN-04, April 2013 (retrieved from http://www.agrodep.org/sites/default/ files/Technical_notes/AGRODEP-TN-04-2_1.pdf).

Starck, S.C. (2012), The Theoretical Foundation of Gravity Modeling: What are the developments that have brought gravity modeling into mainstream economics?, Master Thesis, Copenhagen Business School, August 2012 (retrieved from https://studenttheses.cbs.dk/bitstream/handle/10417/3335/sarah_catherine_starck.pdf ?sequence $=1$ ).

Tinbergen, J. (1962), Shaping the World Economy: Suggestions for an International Economic Policy, New York: The Twentieth Century Funds.

Tobin, J. (1958), Estimation of Relationships for Limited Dependent Variables, Econometrica, 26(1), pp. 24-36.

Vanek, J. (1968), The Factor Proportions Theory: The N-Factor Case, Kyklos, (21), pp. 749755. 


\section{Appendix}

Table A1. The sign test results for GDP and Distance variables for the European Union (EU) member states according to the distance between capitals, in the period from 2001 to 2018

\begin{tabular}{|c|c|c|c|c|c|c|c|c|}
\hline \multirow[t]{2}{*}{ Year } & \multicolumn{4}{|c|}{ GDP } & \multicolumn{4}{|c|}{ Distance } \\
\hline & $\begin{array}{c}\text { Less } \\
\text { than } \\
1,000 \\
\text { km }\end{array}$ & $\begin{array}{c}\text { Betwee } \\
\text { n } 1,000 \\
\text { and } \\
\mathbf{3 , 0 0 0} \\
\text { km }\end{array}$ & $\begin{array}{c}\text { Betwee } \\
\text { n 3,000 } \\
\text { and } \\
\mathbf{5 , 0 0 0} \\
\text { km }\end{array}$ & $\begin{array}{c}\text { More } \\
\text { than } \\
5,000 \\
\text { km }\end{array}$ & $\begin{array}{c}\text { Less } \\
\text { than } \\
1,000 \\
\text { km }\end{array}$ & $\begin{array}{l}\text { Between } \\
1,000 \text { and } \\
3,000 \mathrm{~km}\end{array}$ & $\begin{array}{c}\text { Between } \\
3,000 \text { and } \\
5,000 \mathrm{~km}\end{array}$ & $\begin{array}{c}\text { More } \\
\text { than } \\
\mathbf{5 , 0 0 0} \\
\mathbf{k m}\end{array}$ \\
\hline 2001 & $68 \%$ & $90 \%$ & $98 \%$ & $92 \%$ & $61 \%$ & $28 \%$ & $3 \%$ & $79 \%$ \\
\hline 2002 & $69 \%$ & $90 \%$ & $98 \%$ & $93 \%$ & $61 \%$ & $29 \%$ & $3 \%$ & $79 \%$ \\
\hline 2003 & $69 \%$ & $91 \%$ & $98 \%$ & $93 \%$ & $63 \%$ & $29 \%$ & $3 \%$ & $79 \%$ \\
\hline 2004 & $71 \%$ & $89 \%$ & $98 \%$ & $93 \%$ & $63 \%$ & $29 \%$ & $2 \%$ & $79 \%$ \\
\hline 2005 & $72 \%$ & $90 \%$ & $96 \%$ & $93 \%$ & $64 \%$ & $29 \%$ & $3 \%$ & $79 \%$ \\
\hline 2006 & $71 \%$ & $90 \%$ & $96 \%$ & $93 \%$ & $65 \%$ & $30 \%$ & $4 \%$ & $79 \%$ \\
\hline 2007 & $71 \%$ & $89 \%$ & $94 \%$ & $93 \%$ & $64 \%$ & $29 \%$ & $3 \%$ & $79 \%$ \\
\hline 2008 & $71 \%$ & $87 \%$ & $92 \%$ & $93 \%$ & $66 \%$ & $30 \%$ & $4 \%$ & $79 \%$ \\
\hline 2009 & $70 \%$ & $89 \%$ & $94 \%$ & $92 \%$ & $66 \%$ & $29 \%$ & $3 \%$ & $79 \%$ \\
\hline 2010 & $68 \%$ & $89 \%$ & $92 \%$ & $91 \%$ & $65 \%$ & $29 \%$ & $4 \%$ & $79 \%$ \\
\hline 2011 & $68 \%$ & $90 \%$ & $92 \%$ & $92 \%$ & $65 \%$ & $28 \%$ & $4 \%$ & $80 \%$ \\
\hline 2012 & $68 \%$ & $89 \%$ & $91 \%$ & $92 \%$ & $64 \%$ & $29 \%$ & $5 \%$ & $80 \%$ \\
\hline 2013 & $68 \%$ & $89 \%$ & $92 \%$ & $92 \%$ & $63 \%$ & $29 \%$ & $4 \%$ & $80 \%$ \\
\hline 2014 & $67 \%$ & $90 \%$ & $92 \%$ & $91 \%$ & $63 \%$ & $28 \%$ & $4 \%$ & $80 \%$ \\
\hline 2015 & $62 \%$ & $89 \%$ & $94 \%$ & $91 \%$ & $64 \%$ & $28 \%$ & $3 \%$ & $80 \%$ \\
\hline 2016 & $61 \%$ & $89 \%$ & $94 \%$ & $91 \%$ & $65 \%$ & $28 \%$ & $3 \%$ & $80 \%$ \\
\hline 2017 & $62 \%$ & $89 \%$ & $95 \%$ & $91 \%$ & $65 \%$ & $29 \%$ & $4 \%$ & $79 \%$ \\
\hline 2018 & $61 \%$ & $89 \%$ & $96 \%$ & $91 \%$ & $66 \%$ & $29 \%$ & $3 \%$ & $79 \%$ \\
\hline
\end{tabular}

Source: Authors' calculations

Table A2. The sign test results for GDP and Distance variables for the CEE countries according to the distance between capitals, in the period from 2001 to 2018

\begin{tabular}{|c|c|c|c|c|c|c|c|c|}
\hline \multirow[t]{2}{*}{ Year } & \multicolumn{4}{|c|}{ GDP } & \multicolumn{4}{|c|}{ Distance } \\
\hline & $\begin{array}{c}\text { Less } \\
\text { than } \\
1,000 \\
\text { km }\end{array}$ & $\begin{array}{c}\text { Between } \\
\mathbf{1 , 0 0 0} \\
\text { and } \\
\mathbf{3 , 0 0 0} \\
\text { km }\end{array}$ & $\begin{array}{c}\text { Between } \\
\mathbf{3 , 0 0 0} \text { and } \\
5,000 \mathrm{~km}\end{array}$ & $\begin{array}{c}\text { More } \\
\text { than } \\
\mathbf{5 , 0 0 0} \\
\text { km }\end{array}$ & $\begin{array}{c}\text { Less } \\
\text { than } \\
1,000 \\
\text { km }\end{array}$ & $\begin{array}{c}\text { Between } \\
1,000 \text { and } \\
3,000 \text { km }\end{array}$ & $\begin{array}{c}\text { Betwee } \\
\text { n 3,000 } \\
\text { and } \\
\mathbf{5 , 0 0 0} \\
\text { km }\end{array}$ & $\begin{array}{c}\text { More } \\
\text { than 5,000 } \\
\mathbf{k m}\end{array}$ \\
\hline 2001 & $59 \%$ & $91 \%$ & $100 \%$ & $91 \%$ & $63 \%$ & $26 \%$ & $1 \%$ & $85 \%$ \\
\hline 2002 & $60 \%$ & $92 \%$ & $100 \%$ & $92 \%$ & $64 \%$ & $27 \%$ & $1 \%$ & $85 \%$ \\
\hline 2003 & $60 \%$ & $94 \%$ & $100 \%$ & $92 \%$ & $65 \%$ & $26 \%$ & $1 \%$ & $84 \%$ \\
\hline 2004 & $62 \%$ & $91 \%$ & $97 \%$ & $92 \%$ & $66 \%$ & $26 \%$ & $1 \%$ & $84 \%$ \\
\hline
\end{tabular}




\begin{tabular}{lllllllll}
\hline 2005 & $64 \%$ & $92 \%$ & $97 \%$ & $92 \%$ & $65 \%$ & $26 \%$ & $0 \%$ & $83 \%$ \\
\hline 2006 & $64 \%$ & $92 \%$ & $97 \%$ & $92 \%$ & $66 \%$ & $27 \%$ & $0 \%$ & $83 \%$ \\
\hline 2007 & $63 \%$ & $90 \%$ & $95 \%$ & $92 \%$ & $67 \%$ & $27 \%$ & $1 \%$ & $83 \%$ \\
\hline 2008 & $64 \%$ & $91 \%$ & $93 \%$ & $91 \%$ & $67 \%$ & $27 \%$ & $1 \%$ & $83 \%$ \\
\hline 2009 & $61 \%$ & $91 \%$ & $95 \%$ & $91 \%$ & $68 \%$ & $27 \%$ & $1 \%$ & $83 \%$ \\
\hline 2010 & $59 \%$ & $91 \%$ & $92 \%$ & $90 \%$ & $68 \%$ & $27 \%$ & $1 \%$ & $84 \%$ \\
\hline 2011 & $58 \%$ & $90 \%$ & $91 \%$ & $90 \%$ & $69 \%$ & $27 \%$ & $0 \%$ & $84 \%$ \\
\hline 2012 & $60 \%$ & $88 \%$ & $91 \%$ & $91 \%$ & $63 \%$ & $26 \%$ & $1 \%$ & $84 \%$ \\
\hline 2013 & $60 \%$ & $89 \%$ & $92 \%$ & $90 \%$ & $65 \%$ & $27 \%$ & $0 \%$ & $85 \%$ \\
\hline 2014 & $58 \%$ & $92 \%$ & $91 \%$ & $90 \%$ & $65 \%$ & $26 \%$ & $1 \%$ & $85 \%$ \\
\hline 2015 & $54 \%$ & $91 \%$ & $94 \%$ & $89 \%$ & $64 \%$ & $26 \%$ & $0 \%$ & $86 \%$ \\
\hline 2016 & $52 \%$ & $91 \%$ & $95 \%$ & $89 \%$ & $65 \%$ & $27 \%$ & $0 \%$ & $85 \%$ \\
\hline 2017 & $53 \%$ & $90 \%$ & $95 \%$ & $89 \%$ & $66 \%$ & $27 \%$ & $1 \%$ & $85 \%$ \\
\hline 2018 & $52 \%$ & $91 \%$ & $95 \%$ & $90 \%$ & $67 \%$ & $27 \%$ & $1 \%$ & $85 \%$ \\
\hline
\end{tabular}

Source: Authors' calculations

Table A3. The sign test results for GDP and Distance variables for the World according to the distance between capitals, in the period from 2001 to 2018

\begin{tabular}{|c|c|c|c|c|c|c|c|c|}
\hline \multirow[t]{2}{*}{ Year } & \multicolumn{4}{|c|}{ GDP } & \multicolumn{4}{|c|}{ Distance } \\
\hline & $\begin{array}{c}\text { Less } \\
\text { than } \\
\mathbf{1 , 0 0 0} \\
\text { km }\end{array}$ & $\begin{array}{c}\text { Between } \\
1,000 \text { and } \\
3,000 \mathrm{~km}\end{array}$ & $\begin{array}{l}\text { Between } \\
3,000 \text { and } \\
5,000 \mathrm{~km}\end{array}$ & $\begin{array}{c}\text { More } \\
\text { than } \\
\mathbf{5 , 0 0 0} \\
\text { km }\end{array}$ & $\begin{array}{c}\text { Less } \\
\text { than } \\
1,000 \\
\text { km }\end{array}$ & $\begin{array}{c}\text { Between } \\
1,000 \text { and } \\
3,000 \mathrm{~km}\end{array}$ & $\begin{array}{l}\text { Between } 3,000 \\
\text { and } 5,000 \mathrm{~km}\end{array}$ & $\begin{array}{c}\text { More than } \\
5,000 \mathrm{~km}\end{array}$ \\
\hline 2001 & $64 \%$ & $86 \%$ & $93 \%$ & $90 \%$ & $51 \%$ & $25 \%$ & $15 \%$ & $69 \%$ \\
\hline 2002 & $65 \%$ & $86 \%$ & $92 \%$ & $90 \%$ & $50 \%$ & $26 \%$ & $15 \%$ & $69 \%$ \\
\hline 2003 & $66 \%$ & $87 \%$ & $92 \%$ & $90 \%$ & $50 \%$ & $25 \%$ & $15 \%$ & $69 \%$ \\
\hline 2004 & $67 \%$ & $86 \%$ & $93 \%$ & $89 \%$ & $50 \%$ & $25 \%$ & $14 \%$ & $69 \%$ \\
\hline 2005 & $68 \%$ & $86 \%$ & $92 \%$ & $89 \%$ & $50 \%$ & $26 \%$ & $14 \%$ & $69 \%$ \\
\hline 2006 & $68 \%$ & $86 \%$ & $92 \%$ & $89 \%$ & $51 \%$ & $26 \%$ & $15 \%$ & $68 \%$ \\
\hline 2007 & $67 \%$ & $86 \%$ & $91 \%$ & $89 \%$ & $51 \%$ & $25 \%$ & $14 \%$ & $68 \%$ \\
\hline 2008 & $68 \%$ & $86 \%$ & $90 \%$ & $88 \%$ & $51 \%$ & $25 \%$ & $15 \%$ & $68 \%$ \\
\hline 2009 & $66 \%$ & $86 \%$ & $91 \%$ & $88 \%$ & $53 \%$ & $26 \%$ & $15 \%$ & $68 \%$ \\
\hline 2010 & $65 \%$ & $86 \%$ & $91 \%$ & $88 \%$ & $52 \%$ & $26 \%$ & $14 \%$ & $68 \%$ \\
\hline 2011 & $65 \%$ & $86 \%$ & $91 \%$ & $88 \%$ & $52 \%$ & $25 \%$ & $15 \%$ & $68 \%$ \\
\hline 2012 & $64 \%$ & $86 \%$ & $91 \%$ & $88 \%$ & $53 \%$ & $25 \%$ & $15 \%$ & $67 \%$ \\
\hline 2013 & $64 \%$ & $86 \%$ & $91 \%$ & $89 \%$ & $53 \%$ & $25 \%$ & $14 \%$ & $67 \%$ \\
\hline 2014 & $64 \%$ & $87 \%$ & $90 \%$ & $88 \%$ & $53 \%$ & $25 \%$ & $14 \%$ & $67 \%$ \\
\hline 2015 & $63 \%$ & $87 \%$ & $92 \%$ & $89 \%$ & $52 \%$ & $25 \%$ & $14 \%$ & $67 \%$ \\
\hline 2016 & $62 \%$ & $87 \%$ & $92 \%$ & $89 \%$ & $52 \%$ & $25 \%$ & $14 \%$ & $66 \%$ \\
\hline 2017 & $63 \%$ & $87 \%$ & $92 \%$ & $89 \%$ & $53 \%$ & $25 \%$ & $14 \%$ & $67 \%$ \\
\hline 2018 & $62 \%$ & $86 \%$ & $93 \%$ & $90 \%$ & $56 \%$ & $27 \%$ & $13 \%$ & $67 \%$ \\
\hline
\end{tabular}

Source: Authors' calculations 
Figure A1. The sign test results for the GDP variable for Croatia according to the GDP value of import trade partner of a country, according to the distance between capitals, in 2018
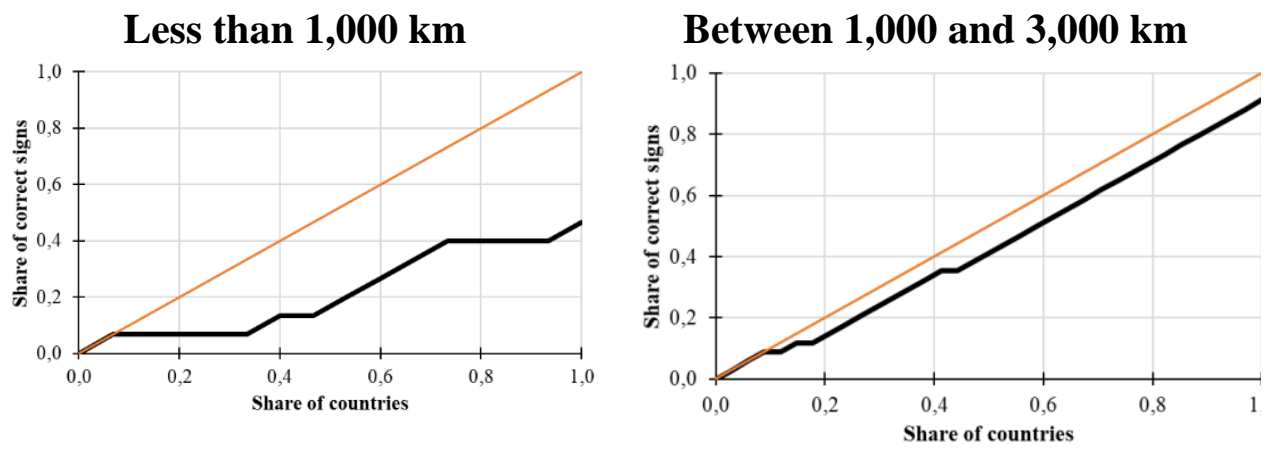

Between 3,000 and 5,000 km
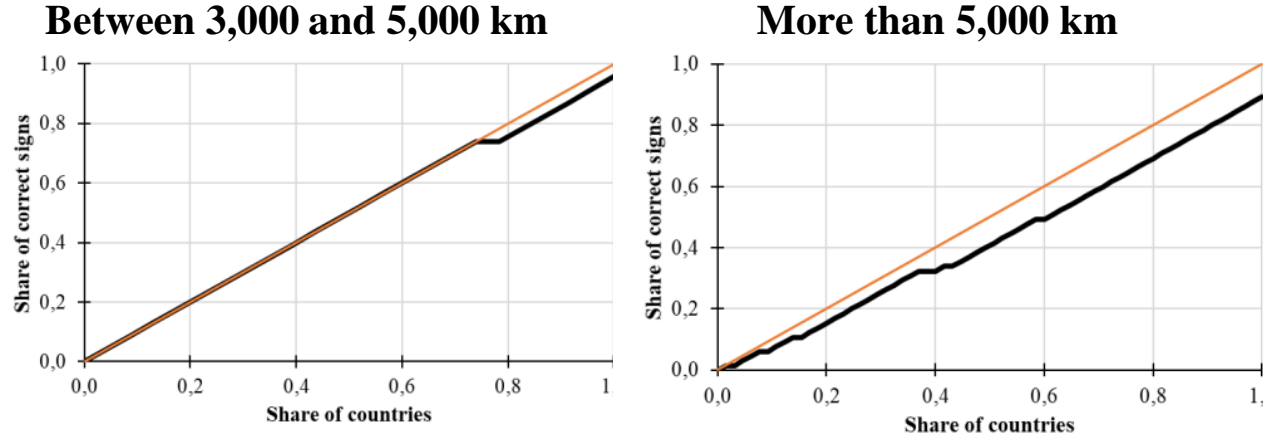

Source: Authors' calculations 
Figure A2. The sign test results for the Distance variable for Croatia according to the Distance value of import trade partner of a country, according to the distance between capitals, in 2018
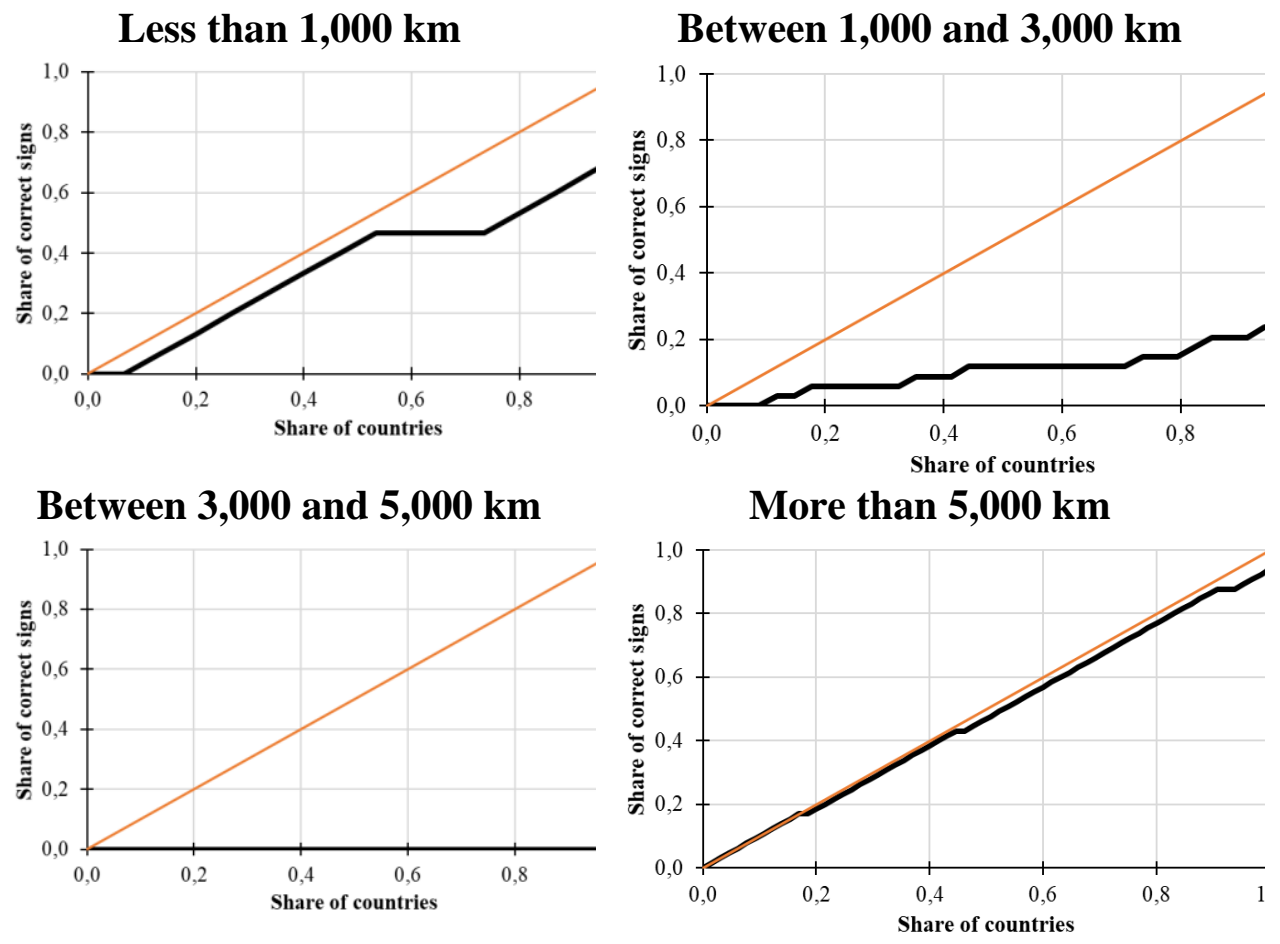

Source: Authors' calculations 


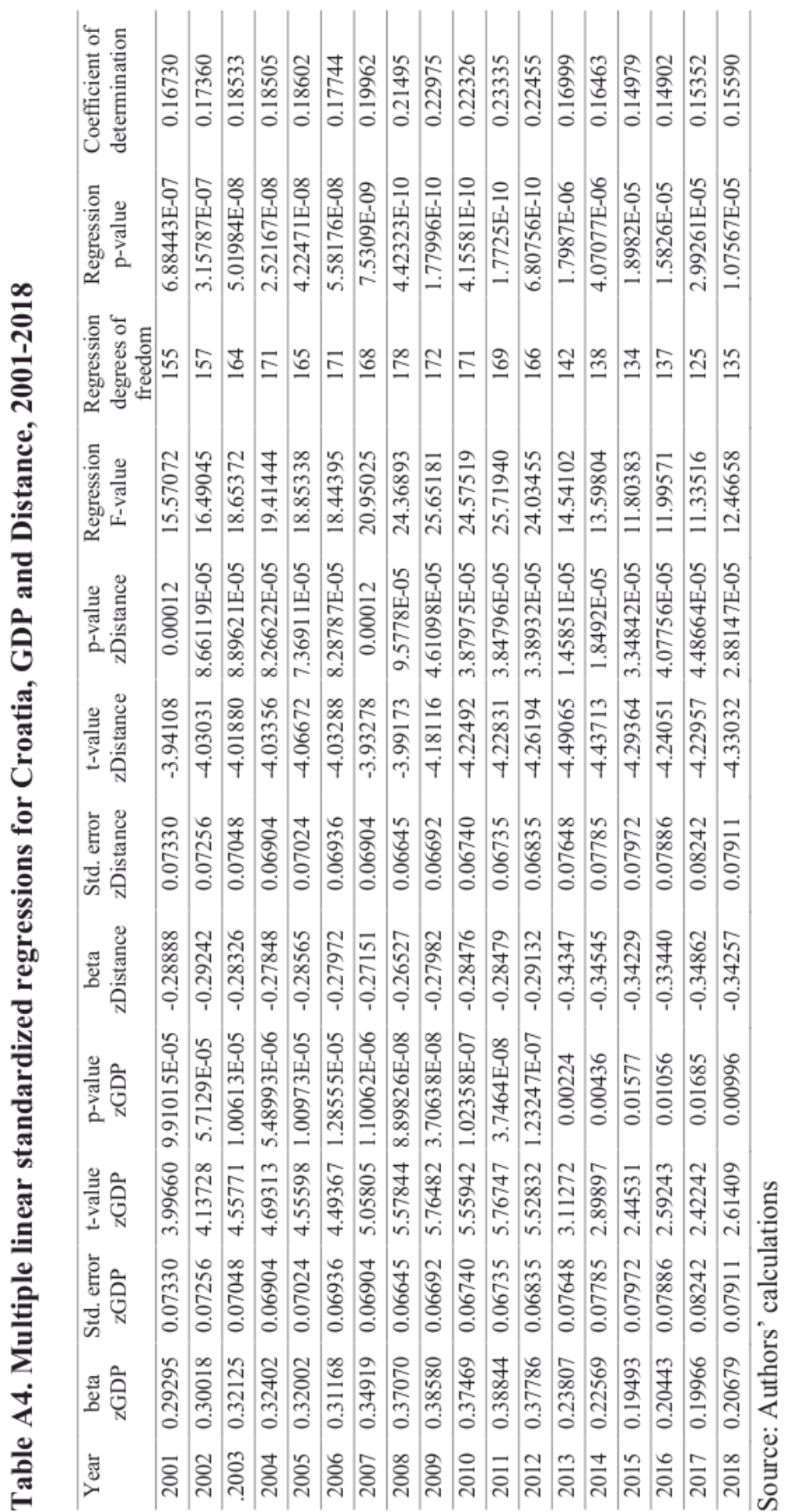

